


\title{
Early childhood environment, breastfeeding and the formation of preferences*
}

\author{
Armin Falk and Fabian Kosse \\ Institute on Behavior and Inequality (briq) \& University of Bonn
}

December 2016

\begin{abstract}
This study provides insights on the role of early childhood family environment within the process of preference formation. We start by presenting evidence showing that breastfeeding duration is a valid measure of the quality of early childhood environment. In the main analysis, we then investigate how early childhood environment affects the formation of fundamental economic preferences such as time, risk, and social preferences. In a sample of preschool children we find that longer breastfeeding duration is associated with higher levels of patience and altruism as well as a lower willingness to take risk. Repeating the analysis on a sample of young adults indicates that the observed pattern is replicable and persists into adulthood. Importantly, in both data sets our findings are robust when controlling for cognitive ability and parental socio-economic status. We can further rule out that the results are purely driven by nutritional effects of breastfeeding. Altogether, our findings strongly suggest that early childhood environment as measured by breastfeeding duration systematically and persistently affects preference formation.
\end{abstract}

Keywords: Time preferences, risk preferences, altruism, experiments with children, origins of preferences, childhood environment, breastfeeding.

JEL-Codes: C91, D64, D90, D81, J13

*We thank Björn Bartling, Ernst Fehr, Michel Maréchal, Friedhelm Pfeiffer, Daniel Schunk, Jürgen Schupp, Katharina Spieß and Gert Wagner for cooperation in the project on mother and child preferences, as well as Flávio Cunha, Meike Deckers, Thomas Deckers, Thomas Dohmen, Philipp Eisenhauer, Lorenz Götte, James Heckman, John Eric Humphries, Martin Kocher, Katherina Kosse, Philipp Legetporer, Pia Pinger, Christopher Roth, Hannah Schildberg-Hörisch, Matthias Sutter, Ulf Zölitz and participants at various seminars for valuable comments and discussions. Armin Falk gratefully acknowledges financial support through the Leibniz Programme of the German Science Foundation (DFG). Contact: armin.falk@uni-bonn.de, kosse@uni-bonn.de. 


\section{Introduction}

Time, risk, and social preferences are key building blocks of any economic model and fundamentally determine behavior and life outcomes. ${ }^{1}$ Despite their fundamental importance, little is known about the origin of heterogeneities in these preferences. $^{2}$ This paper seeks to contribute to a better understanding of the preference formation process focusing on the role of the quality of early childhood environment. It is widely accepted that early childhood is a critical and sensitive period in human development (Ainsworth and Bowlby, 1991; Cunha and Heckman, 2007; Fehr et al., 2008, 2013; Almås et al., 2010; Currie and Almond, 2011; Sutter and Glätzle-Rützler, 2015), but it is largely unknown how early childhood environment affects key economic preferences. Addressing this issue requires a combination of two types of typically unconnected sources of information, (i) valid measures of the quality of family environment in early childhood and (ii) preferences later in life: Measuring the quality of early childhood environment requires a valid description of an individual's environment in the very first months and years of life. ${ }^{3}$ Due to the complexity of incentivized choice experiments, valid measures concerning time, risk, and social preferences are usually only elicited for adolescents and adults, however.

To shed light on the relation between early childhood environment and preference formation, this paper makes two main contributions: First, we suggest a strategy which allows us to connect measures of the early childhood environment with measures of preferences, elicited later in life. In particular, we suggest using breastfeeding duration as an easy-to-collect measure for the quality of early childhood environment. Relevance of breastfeeding duration requires that mothers reliably remember breastfeeding duration and that breastfeeding duration is informative about crucial

\footnotetext{
${ }^{1}$ Time preferences are relevant for any type of investment decision because investment, by its nature, requires patience, i.e., a willingness to forgo current consumption and wait, in order to earn a higher return in the future (Frederick et al., 2002; Chabris et al., 2008; Sutter et al., 2013). Similarly, most decisions involve uncertainty, and risk preferences determine how someone behaves in the presence of uncertainty (Jaeger et al., 2010; Dohmen et al., 2011). Moreover, almost all social interactions are shaped by social preferences, as e.g., altruism (Eckel and Grossman, 1996; Fehr and Fischbacher, 2003)

${ }^{2}$ While there is general evidence that, next to genes, social environment is an important source of heterogeneity (Cesarini et al., 2009; Benjamin et al., 2012), less is known about which aspects of the social environment affect preferences and in which direction. Exceptions are, e.g., Chen (2013) providing evidence on the effect of language on time preferences or Bauer et al. (2014) and Almås et al. (2016) providing evidence on the relation of parental education and social preferences. Angerer et al. (2016) present evidence on the effect of language on the development of cooperation. For evidence on the effect of family background on another important preference, willingness to compete, see Almås et al. (2015).

${ }^{3}$ To elicit valid and reliable measures of the quality of family environment or "investments in children" is extremely difficult even if there is no time gap, see, e.g., Culhane et al. (2016) and the discussion in section 2 herein.
} 
aspects of early childhood environment. The first main contribution of our study is to provide evidence that these requirements hold. We present new evidence showing that breastfeeding duration is a valid measure of the quality of early childhood environment and the quality of parenting in general. Using two existing panel data sets we find that breastfeeding duration is closely associated with established measures of the quality of the environment, such as measures on time spending within the family (Cunha et al., 2010; Cunha and Heckman, 2008) or describing the home environment (Bradley and Caldwell, 1980). In addition, we refer to findings from the epidemiological literature indicating that mothers do in fact have a rather precise recollection of how long they breastfed (Li et al., 2005).

Building on these findings, our second main contribution is to relate breastfeeding duration to experimental measures of time, risk and social preferences. In a sample of preschool children, we find that a higher quality of early childhood environment, measured by longer breastfeeding duration, is significantly associated with lower levels of risk seeking and higher levels of patience and altruism. We acknowledge that our empirical strategy does not exploit exogenous variation in the quality of early childhood environment. We can, however, rule out purely nutritional effects of breastfeeding in this context. Moreover, we demonstrate that the observed effects are robust conditional on individual characteristics of children (such as gender, age, and IQ), parental income and education as well as preferences and IQ of mothers. ${ }^{4}$ Including these covariates controls for intergenerational transmission of preferences ${ }^{5}$ and important factors which may systematically vary with breastfeeding decisions.

Further support for the observed effects comes from the analysis of a sample of young adults. This analysis serves two purposes. First, we show that the observed preference pattern is replicated in an unrelated sample. Second, given that the second sample consists of adults, we demonstrate that the effects observed in children are enduring and persist into adulthood. We thus provide convergent evidence on the role of early childhood environment for the formation of key economic preferences.

We believe that the validation of breastfeeding duration as a measure of early childhood environment can turn out to provide useful insights in future research. Studies interested in uncovering the effects of personality on outcomes often suffer from lack of control for environment early in life. Measures of personality traits, such as preferences, Big Five or Locus of Control $^{6}$, are typically collected in adults, com-

\footnotetext{
${ }^{4}$ See, e.g., Burks et al. (2009) and Dohmen et al. (2010) for the relation of preferences and IQ and Black et al. (2009) for the intergenerational transmission of IQ.

${ }^{5}$ See Bartling et al. (2010), Dohmen et al. (2012), Kosse and Pfeiffer (2012) and Alan et al. (2014) for evidence on the intergenerational transmission of preferences.

${ }^{6}$ For an overview about personality measures and their relations see Becker et al. (2012).
} 
bined with information about environmental factors at the time of the interview. Thus, there is an inevitable time gap between conditions at birth and personality measures. Knowing more about conditions, early in life, could help to eliminate problems of reverse causality and omitted variable bias. Our claim is not that breastfeeding duration is a "complete" indicator; nor that it is a perfect substitute for more detailed measures of early childhood environment. What we show, however, is that it is an easy-to-collect and valid measure to proxy for early life conditions. Given the importance of the latter in the context of personality development, we think that including measures of breastfeeding in large-scale surveys would be very useful. ${ }^{7}$

The remainder of the paper is organized as follows: In section 2, we validate breastfeeding duration as a measure of the quality of early childhood environment. In section 3, we explore the association between early childhood environment and time, risk and social preferences, using samples of preschool children and young adults, respectively. Section 4 concludes.

\section{Measuring the quality of early childhood envi- ronment}

The impact of breastfeeding has been studied in various fields (Mortensen, 2015; Del Bono and Rabe, 2012; Chen and Rogan, 2004; Heinrichs et al., 2002; Uauy and De Andraca, 1995). In this section, we provide new evidence for the convergent and discriminant validity of breastfeeding duration as a measure of the quality of early childhood environment. ${ }^{8}$ In general, it is very difficult to capture all facets of the early childhood environment in one comprehensive measure (Culhane et al., 2016). Established strategies to identify the underlying "quality of environment" or "investment in children" are to use data on time spending within the family (e.g., Cunha et al., 2010; Cunha and Heckman, 2008) or data describing the home environment ${ }^{9}$ (e.g., Blomeyer et al., 2009; Todd and Wolpin, 2007). We build on these strategies

\footnotetext{
${ }^{7}$ See also the discussion in Currie and Almond (2011) on general data constraints regarding research on the effects of early childhood environment.

${ }^{8}$ Note that the extent to which breastfeeding duration is a measure of the quality of early childhood environment varies between cultures. Our validation concerns Western societies, especially Germany. In developing countries the decision to breastfeed may be determined by very different considerations, see, e.g., Jayachandran and Kuziemko (2011). For a more detailed discussion see section 4.

${ }^{9}$ An often used tool to describe the home environment is the HOME scale (Home Observation Measurement of the Environment) designed by Bradley and Caldwell (1980). It captures a wide range of interactions and environmental factors but was also criticized due to its relatively poor item-response-theory properties (Culhane et al., 2016).
} 
and show that breastfeeding duration is highly correlated with quality-time spending as well as stimulation and support available in the home environment. In sum this paper makes use of five independent complementary data sets all involving information about breastfeeding duration. For an overview see Table A1.

Our main validation analysis is based on data from the German Socio-Economic Panel (SOEP) (Wagner et al., 2007), a large representative panel of the German population including very detailed information about the family environment in the first three years of life. The analysis consists of about 550 children of the birth cohorts 2004-2007 and their natural parents. The share of children who were breastfed is $88 \%$, of these, the average duration of breastfeeding ${ }^{10}$ is 7.6 months (std. dev. is 6.0 months). Figure A1 displays the cumulative distribution of breastfeeding duration and reveals substantial variation. ${ }^{11}$

When their children are between two and three year years old, mothers are asked how many times in the last 14 days she, or the main caregiver, has engaged in nine particular activities together with their child. A principal component analysis concerning responses to all potential activities yields three components (see Table A2). The first component reflects activities which involve face-to-face contact and intense interaction between mother and child such as reading or telling children's stories or singing children's songs with the child (high quality time). The second component reflects activities with less intense interaction and direct contact such as going shopping or visiting other families with the child (medium quality time). The third component comprises watching TV or videos (low quality time).

In Table 1 we report results of multivariate regression analyses to investigate determinants of being breastfed at all (column 1) and of breastfeeding duration given a child was breastfed (column 2). Results in column 1 indicate that being breastfed at all is strongly determined by physical health problems of the mother $(p<0.01)$ as well as socio-economic status $(p<0.05)$. There is, however, no jointly significant relation to the quality of time spent with the child (see bottom of Table 1 for Wald-tests). In contrast, results in column 2 reveal that breastfeeding duration is positively correlated with high quality time spending $(p<0.01)$ but not correlated with health conditions of the mother or maternal education and household income (see also Wald-test).

\footnotetext{
${ }^{10}$ In our context the term breastfeeding duration is defined as the period of feeding breast milk, also if breastfeeding is accompanied by feeding other liquid or solid foods (partial breastfeeding).

${ }^{11}$ As we show below the decision to breastfeed at all is mainly driven by maternal health and socio economic status. In contrast, the variation in breastfeeding duration reflects heterogeneities in the quality of time spent with children and other measures of quality of early childhood environment.
} 


\begin{tabular}{|c|c|c|}
\hline & $\begin{array}{l}\text { Breastfed } \\
(\text { yes }=1) \\
\text { Binary } \\
\text { Probit } \\
\quad(1)\end{array}$ & $\begin{array}{l}\text { Duration of } \\
\mathrm{BF}(\text { if } \mathrm{BF}>0) \\
\text { in months } \\
\text { OLS } \\
(2)\end{array}$ \\
\hline \multicolumn{3}{|l|}{ Parent-child interaction } \\
\hline Component high quality time at age $2-3$ (standardized) & $\begin{array}{l}0.027^{*} \\
(0.014)\end{array}$ & $\begin{array}{c}1.238^{* * *} \\
(0.247)\end{array}$ \\
\hline Component medium quality time at age $2-3$ (standardized) & $\begin{array}{l}-0.015 \\
(0.014)\end{array}$ & $\begin{array}{l}-0.509^{*} \\
(0.281)\end{array}$ \\
\hline Component low quality time at age $2-3$ (standardized) & $\begin{array}{l}-0.006 \\
(0.014)\end{array}$ & $\begin{array}{l}-0.519^{*} \\
(0.296)\end{array}$ \\
\hline $\begin{array}{l}\text { Physical health problems of mother } \\
\text { (last third of pregnancy and } 3 \text { months after birth) }\end{array}$ & $\begin{array}{c}-0.113^{* * *} \\
(0.028)\end{array}$ & $\begin{array}{l}-0.435 \\
(0.626)\end{array}$ \\
\hline \multicolumn{3}{|l|}{ Socio-economic status } \\
\hline College degree mother & $\begin{array}{c}0.141^{* * *} \\
(0.047)\end{array}$ & $\begin{array}{c}1.098 \\
(0.715)\end{array}$ \\
\hline Log net household income & $\begin{array}{l}-0.009 \\
(0.029)\end{array}$ & $\begin{array}{c}0.529 \\
(0.586)\end{array}$ \\
\hline Cohort dummies & Yes & Yes \\
\hline $\begin{array}{l}\text { Wald-tests: } \\
\text { - all parent-child interaction }=0 \\
\text { - all socio-economic status }=0 \\
\text { Observations }\end{array}$ & $\begin{array}{c}\chi^{2}=4.00 \\
\chi^{2}=9.06^{* *} \\
552\end{array}$ & $\begin{array}{c}F=9.57^{* * *} \\
F=2.12 \\
484\end{array}$ \\
\hline
\end{tabular}

Table 1: Determinants of breastfeeding duration. Source: SOEP (2012). Coefficients are average marginal effects. For estimation of the components of parent-child interaction, see Table A2. Physical health problems of mother is a dummy indicating rather bad or very bad health in last third of pregnancy or the first three months after birth. College degree mother is a dummy variable indicating whether mother holds a university or technical college degree. Net household income is the self-reported net household income. For Wald-tests concerning the OLS (Probit) estimations $F-\left(\chi^{2}-\right)$ values are displayed. Clustered standard errors (at household level) in parentheses; ${ }^{* * *}$, **, ${ }^{*}$ indicate significance at $1-, 5$-, and 10-percent level, respectively.

Using other measures of early childhood environment or investments in children, and other data sets, confirms these results. Table A3 additionally reports positive correlations of breastfeeding duration with quality of stimulations and support using the HOME inventory (Bradley and Caldwell, 1980; Blomeyer et al., 2009), life satisfaction of the mother in the year of the child's birth and how important it is for the mother to have children.

In sum, the analysis shows that breastfeeding duration proxies as broad range of positive early social environment-related factors and investments in children. It justifies the interpretation that breastfeeding duration is determined by an underlying quality of early childhood environment and an error term, which could reflect, e.g., local breastfeeding traditions. If this error term is uncorrelated with the underlying 
quality of early childhood environment (classical error-in-variables assumptions) the estimation coefficients on breastfeeding duration reported in sections 3 , represent a lower bound estimate of the effect of the quality of early childhood environment.

Since never being breastfed is to a large extent determined by health shocks, we will restrict the main analysis to children who were breastfed to limit the attenuation bias. In section 3.3.2, we will also use data of the non-breastfed children to disentangle direct nutritional and environment-related effects of breastfeeding.

\section{Main analysis}

The validation of breastfeeding duration as a measure of the quality of early childhood environment sets the stage for our main analysis. We measured time, risk, and social preferences using established and incentivized experiments and additionally collected information concerning early childhood environment by maternal recall about breastfeeding duration ( $\mathrm{Li}$ et al., 2005). This procedure enables us to study the effect of early childhood environment on the formation of fundamental preferences in two independent data sets. The first is a preschool children sample that allows analyzing the effect of interest early in life and within the development process. The second data set repeats the setting for a sample of young adults. Comparing our findings between these two data sets enables us to study robustness and whether the observed pattern persists into adulthood.

\subsection{Data description: Preschool children sample}

Sample and survey. Data concerning preschool children consists of two independent sub-data sets ${ }^{12}$. These data sets feature experimental measures concerning time preferences (Part A), risk preferences (Part B) and altruism (Part B) of which all are conducted with preschool children and their mothers. All experiments and interviews were conducted by specially trained and experienced interviewers from the same professional surveying company that administers the SOEP. The data sets include IQ and preference measures as well as information on socio-economic background. The time preference experiment was conducted at the families' own homes (see below) while the experiments with children in Part B were conducted in a separate room located at the children's day-care centers. The interviews with the mothers generally took place at their own homes (Part A and B). Every mother participated in a two-part computer assisted personal interview (CAPI). In the first part mothers answered a detailed survey including demographic and socio-economic

\footnotetext{
${ }^{12}$ The data sets are administered by the DIW Berlin under the name MuKi.
} 
questions, as well as, questions concerning breastfeeding duration (all questions are based on SOEP questionnaires) (Wagner et al., 2007). In the second part mothers took part in an IQ test and incentivized behavioral experiments.

All experiments were run using real incentives and all children had to answer control questions to check understanding of experimental instructions and payment rules. In Part A children decided about gummy bears, while in Part B they could earn chips, which were exchanged for toys at the end of the experiment. In our analysis we only include children who demonstrated understanding of the experiment (control questions and interviewer rating). We additionally exclude children from Part A for whom the mother indicated that her child does not like gummy bears at all or not so much. For non-biological children it is very unlikely that breastfeeding duration is a valid measure of the quality of early childhood environment and therefore we also restrict the analysis to biological children. To receive comparable results we also exclude observations with missing values in covariates from the analysis (see Table A4) ${ }^{13}$. In sum, the preschool sample consists of 307 breastfed children and their natural mothers. 198 mother-child pairs took part in the time preference experiment while 109 pairs took part in experiments to measure risk preferences and altruism. On average, the children were 5.9 years old and $51.5 \%$ are male.

Measures of preferences (children). The experiment concerning children's time preference was a lab-in-the-field adaption of the "marshmallow experiment" of Walter Mischel (Mischel et al., 1989) and was conducted at the families' own homes. ${ }^{14}$ Mother, child and the interviewer remained in the same room. Before the detailed interview of the mother started, the interviewer opened a pack of gummy bears ${ }^{15}$ and explained that the child could either eat them now or wait until the end of the mother's interview and receive an additional pack. Thus, children were facing the decision between receiving a smaller reward (one pack of gummy bears) sooner, or waiting and receiving a larger reward (two packs of gummy bears) later. 23.2\% of the children took the opened pack before the interview ended. They are classified as impatient. $76.8 \%$ waited and received two packs of gummy bears. They are classified as patient ${ }^{16}$.

To measure children's risk preferences, they played an adaption of the devil's task (Slovic, 1966). They were presented with 10 indistinguishable closed boxes of which

\footnotetext{
${ }^{13}$ Not excluding observations with missing values in covariates yields to very similar results, for comparison see Table 2 and Table A5.

${ }^{14}$ For a detailed description see Bartling et al. (2010).

${ }^{15}$ Gummy bears were used since they are more popular in Germany than marshmallows.

${ }^{16}$ Psychologists usually use the term self-control in this context. For an overview on time preferences, including a discussion on labeling, see Frederick et al. (2002).
} 
nine included a chip and one a robber (in the English original it is a devil). The children could sequentially open as many boxes as they wanted to. They could keep all chips, which they found in the opened boxes, but if they opened the box with the robber, they lost all chips of this round. ${ }^{17}$ The game was played for six rounds and we use the average voluntary stopping point as measure for children's willingness to take risk. ${ }^{18}$ The mean average voluntary stopping point is 5.09 (standard deviation $=2.19)$.

To elicit altruism, we used a distribution choice as in Fehr et al. (2008). The child had to decide between different distributions of chips affecting himself and another anonymously matched child that could be from their own kindergarten group or from another unknown kindergarten. ${ }^{19}$ The child knew whether the receiver was from the own group or not, and we control for the different setting in our analysis. We focus on the costly altruism variant of the game. In this game the children had to decide between two chips for themselves $(2,0)$ or one for themselves and one for the other child $(1,1)$. The $14.9 \%$ children who chose $(1,1)$ are classified as altruistic.

Measures of cognitive ability (children). The children took part in three modules of intelligence tests. Two of them are sub-modules of the Culture Fair Intelligence Test Scale 1 (CFT1) (Weiss, 2006) and measure the fluid intelligence of children. The first submodule was a classification test where the child had to find one out of five symbols which does not fit into the respective row. The second one was a matrix test where the child had to add a fitting pattern to a row of three patterns. Both subtests contain 12 items. The sum of the correct answers builds the fluid intelligence score. The third module was a modified version of the German Peabody Picture Vocabulary Test Revised (PPVT-R) (Bartling et al., 2010), in which the child heard a word and had to match it to one out of four symbols. This test is a verbal scale, which captures culture and education related components of intelligence. The test contains 61 items and the number of correct answers reflects the score of crystallized intelligence of the child. To obtain a joint IQ score of the child we added the standardized fluid and crystallized scores.

\footnotetext{
${ }^{17}$ To avoid frustration for the children, there was a wild card: If the robber occurred under the first opened box, this round was restarted. The wild card could be used once only.

${ }^{18}$ The average voluntary stopping point is not identified for those children who never stopped voluntarily and never had the chance to open the $9^{\text {th }}$ box because the robber always occurred before. For those three children we assume the voluntary stopping point to be the $9^{\text {th }}$ box (the maximum, upper bound) which seems plausible since they opened the $7^{\text {th }}$ or $8^{\text {th }}$ box when they had the chance to do so. The analysis shows very similar results if instead we use the maximum number of actually opened boxes (lower bound) for these children.

${ }^{19}$ Allocation to "ingroup" and "outgroup" treatment was randomized.
} 
Measures of preferences and cognitive ability (mothers). All experiments concerning preferences of mothers were conducted in their own homes as part of a computer assisted personal interview (CAPI). For time and risk preferences, the same procedures and protocols as in Dohmen et al. (2010) were used. Mothers were informed that they would receive potential earnings in form of a cheque sent by mail. To measure time preference, mothers faced the trade-off between receiving $100 €$ "today" and receiving a higher amount in six months. The higher amount offered began at 101.2€ and was increased in 19 further steps of $2.5 \%$ p.a.. To ensure incentive compatibility, one out of seven mothers was paid according to one of her decisions. Both, eligible mothers and decisions for payment were randomly chosen. For our measure of time preferences we use the the smallest amount of money for which mothers preferred the delayed payout. We recoded the measure such that higher values indicate more patience.

Mothers' risk preferences were measured in a similar way. Here, they had to decide between a lottery that pays zero or $300 €$ with equal probabilities and a safe payment. The safe payment increased from $10 €$ to $200 €$ in steps of $10 €$. The probability that one randomly selected decision would be implemented was $1 / 9$. We use the switching row from choosing the lottery to choosing the safe amount as our measure of willingness to take risk.

Mothers' altruism was elicited in the same way as for the children except for the fact that mothers played for money. ${ }^{20}$ Mothers had to decide between $16 €$ for themselves and $4 €$ for another participating mother $(16,4)$ or $10 €$ for themselves and $10 €$ for the other participant $(10,10)$. Mothers who chose $(10,10)$ are classified as altruistic. $84.2 \%$ percent of the mothers chose the altruistic distribution.

Cognitive ability of the mothers was elicited using the Symbol-Digit-Test (SDT) (Lang et al., 2005), a modified submodule of the Wechsler Adult Intelligence Scale (HAWIE-R) (Tewes, 1994). In the SDT mothers had to match as many numbers and symbols as possible according to a correspondence list within 90 seconds. The resulting score correlates well with test scores from other well-established intelligence tests (Lang et al., 2005, 2007).

\subsection{Data description: Young adults sample}

Sample and survey. Data for the young adults feature the same preferences as for the preschool children and were collected at the BonnEconLab at the University of Bonn. We used zTree (Fischbacher, 2007) to run the experiments and ORSEE

\footnotetext{
${ }^{20}$ For details see Bartling et al. (2009).
} 
(Greiner, 2004) to recruit the subjects. 211 students took part in a series of experiments and surveys, and answered an additional take-home survey in which they were requested to ask their mother how long they were breastfed. 175 of them indicate that they were breastfed and reported breastfeeding durations. The students further provided information concerning socio-economic status of their parents and own school achievements. In the analysis, we use math grades as a proxy for intelligence (Spinath et al., 2006). Mean age of students was 21.8 years and $44.6 \%$ of them are male.

Measures of preferences. Time and risk preferences of students were elicited in a similar manner as for the mothers in the preschool sample and as in Dohmen et al. (2010). To measure students' time preferences they faced trade-offs between a smaller but sooner reward and increasingly larger but delayed rewards. The smaller sooner reward was fixed to 1600 points. The larger later reward also started at 1600 points and was increased in 24 steps of $2.5 \%$ p.a. (100 points correspond to $0.8 €$ ). To reduce measurement error, students played four different versions of this experiment in random order. In the first version the earlier payment date was "today" and the later in six months. In the second version the earlier payment date was also "today" but the later was in 12 months. In the third version the payment dates were in six and in 12 months, respectively. The fourth version was a perturbation of the second version. Participants were informed that one decision would be randomly selected and paid. They also knew that the money was sent by mail irrespective of the payment date. To aggregate the decisions over all four versions of the experiment we use the average of the first switching rows from the sooner to the later payment as our measure of the students' time preference. For a more intuitive comparison with the results of the children the measure was reversed such that higher values indicate more patience.

To measure risk preferences of students they played two versions of an experiment where they had to decide between a lottery that pays zero or 1000 points with equal probability, and a successively increasing safe payment. The safe payment increased in steps of 50 points from zero to 1000 . The two versions were played in random order and differed only in the exact size of the increase: In one version the increase in safe payments was in steps of exactly 50 points while in the other the increase was 50 points $+/-10$ percent, i.e., with slight perturbation. One decision out of both experiments was paid. We take the average first switching row from lottery to safe payment as our measure of the willingness to take risks.

To measure altruism, we used three questionnaire items. The questionnaire frame was "How would you assess your willingness to share with others without expecting 
anything in return, concerning the following groups ...?" combined with the items "people from my neighborhood", "people from my city" and "strangers". Each item was answered on an 11-point Likert scale. We aggregated the survey answers using a principal component analysis. ${ }^{21}$

\subsection{Results}

In the following we explore the preferences pattern that arose in response to the quality of early childhood environment measured by breastfeeding duration. We also report effects conditional on individual and parental characteristics to disentangle the effects of the quality of early childhood environment from direct transmission of preferences or purely monetary resources. As described in section 2, we exclude never breastfed children from the main analysis in section 3.3.1 but compare breastfed and non-breastfed children in section 3.3.2.

\subsubsection{Breastfeeding duration and preference formation}

We first analyze our preschool children sample and then repeat the analysis using our sample of young adults to test if the observed pattern is replicable and persists into adulthood. Our main result is displayed in Panel A of Table 2. The dependent variable is the child's respective preference, which is regressed on breastfeeding duration. Columns 1, 3 and 5 show the estimates without further controls. The results indicate that a longer duration of breastfeeding is associated with a lower willingness to take risk and higher levels of patience and altruism. Columns 2, 4 and 6 include controls which might affect breastfeeding duration and preference formation simultaneously (Jayachandran and Kuziemko, 2011; Currie and Moretti, 2003). These controls include child characteristics (e.g., gender and IQ), parental socio-economic status (SES) as well as preferences and IQ of the mother. Conditioning on these variables is an important robustness check. For example, if more patient mothers breastfed longer, the omission of mother's time preference would potentially lead to an overestimation of the effect of early childhood environment on a child's patience. Results in columns 2, 4 and 6 show that the observed pattern is robust to including these controls. The coefficients of the control variables (see Table A4) are in line with previous findings, e.g., we find an intergenerational correlation regarding time preferences (Bartling et al., 2010; Kosse and Pfeiffer, 2012) and gender differences regarding risk preferences (Croson and Gneezy, 2009). A comparison of the coefficients of breastfeeding duration to those of the control variables further reveals

\footnotetext{
${ }^{21}$ We yield very similar results in the later analysis if we use voluntary working hours for the benefit of charities as measure of altruism, but not for using incentivized donations to charities.
} 
the quantitative relevance of early childhood environment. To illustrate, a simulated change in breastfeeding duration from the 25\%-percentile (2 months) to the $75 \%$ percentile ( 9 months), increases the probability of being patient by $17.1 \%$ points (from $69.0 \%$ to $86.1 \%$ ), which, e.g., exceeds the average effect of a two standard deviations increase in mother's patience.

Wald tests reveal significant joint effects of child characteristics as well as IQ and preferences of the mother on the child's preferences, but, conditional on breastfeeding duration, no significant effect of the socio-economic environment. These results suggest that the quality of early childhood environment and preferences of the mother play a more crucial role in the process of preference formation than intellectual or monetary inputs.

\begin{tabular}{|c|c|c|c|c|c|c|}
\hline & \multicolumn{2}{|c|}{ Time } & \multicolumn{2}{|c|}{ Risk } & \multicolumn{2}{|c|}{ Altruism } \\
\hline & $(1)$ & $(2)$ & $(3)$ & (4) & $(5)$ & $(6)$ \\
\hline \multicolumn{7}{|l|}{ Panel A preschool children } \\
\hline Dependent variable & \multicolumn{2}{|c|}{ Binary } & \multicolumn{2}{|c|}{ Standardized } & \multicolumn{2}{|c|}{ Binary } \\
\hline Type of estimation & \multicolumn{2}{|c|}{ Probit } & \multicolumn{2}{|c|}{ OLS } & \multicolumn{2}{|c|}{ Probit } \\
\hline Duration of breastfeeding (in months) & $\begin{array}{l}0.023^{* * *} \\
(0.008)\end{array}$ & $\begin{array}{l}0.024^{* * *} \\
(0.008)\end{array}$ & $\begin{array}{l}-0.032^{* *} \\
(0.016)\end{array}$ & $\begin{array}{c}-0.029^{*} \\
(0.017)\end{array}$ & $\begin{array}{l}0.016^{* *} \\
(0.007)\end{array}$ & $\begin{array}{l}0.017^{* * *} \\
(0.006)\end{array}$ \\
\hline Individual characteristics & No & Yes & No & $\mathrm{Yes}^{+}$ & No & Yes \\
\hline Parental SES & No & Yes & No & Yes & No & Yes \\
\hline Preferences and IQ of mother & No & $\mathrm{Yes}^{+}$ & No & Yes & No & Yes \\
\hline Task specific controls & Yes & Yes & No & No & Yes & Yes \\
\hline Observations & 198 & 198 & 109 & 109 & 101 & 101 \\
\hline (Pseudo) R-squared & 0.066 & 0.157 & 0.024 & 0.142 & 0.090 & 0.185 \\
\hline \multicolumn{7}{|l|}{ Panel B young adults } \\
\hline Dependent variable & \multirow{2}{*}{\multicolumn{2}{|c|}{$\begin{array}{c}\text { Standardized } \\
\text { OLS }\end{array}$}} & \multirow{2}{*}{\multicolumn{2}{|c|}{$\begin{array}{l}\text { Standardized } \\
\text { OLS }\end{array}$}} & \multirow{2}{*}{\multicolumn{2}{|c|}{$\begin{array}{c}\text { Standardized } \\
\text { OLS }\end{array}$}} \\
\hline Type of estimation & & & & & & \\
\hline Duration of breastfeeding (in months) & $\begin{array}{l}0.041^{* *} \\
(0.016)\end{array}$ & $\begin{array}{l}0.037^{* *} \\
(0.016)\end{array}$ & $\begin{array}{l}-0.037^{*} \\
(0.021)\end{array}$ & $\begin{array}{l}-0.041^{* *} \\
(0.019)\end{array}$ & $\begin{array}{l}0.048^{* * *} \\
(0.016)\end{array}$ & $\begin{array}{l}0.045^{* * *} \\
(0.015)\end{array}$ \\
\hline Individual characteristics & No & $\mathrm{Yes}^{+}$ & No & Yes & No & Yes \\
\hline Parental SES & No & Yes $^{+++}$ & No & Yes $^{+++}$ & No & $\mathrm{Yes}^{++}$ \\
\hline Observations & 175 & 175 & 175 & 175 & 175 & 175 \\
\hline R-squared & 0.028 & 0.222 & 0.021 & 0.210 & 0.037 & 0.165 \\
\hline
\end{tabular}

Table 2: The effect of the quality of early childhood environment on preferences of preschool children and young adults. Displayed coefficients are average marginal effects with respective preference as dependent variable and robust standard errors in parentheses. Panel A shows results for the sample of preschool children (Part A and B). Panel B shows results for the sample of young adults. The complete specifications and estimation results are shown in Tables A4 and A6. ${ }^{* * *}$, ${ }^{* *},{ }^{*}$ indicate significance at $1-, 5-$, and 10-percent level, respectively. ${ }^{+++},{ }^{++},{ }^{+}$indicate significance at 1-, 5-, and 10-percent level of Wald-tests testing the hypothesis that all coefficients of the respective category are zero.

To study robustness of the reported pattern and potential persistence into adulthood we study a sample of university students. We repeat the same analysis as for the preschool sample and report the results in Panel B of Table 2. Columns 1, 3 and 
5 display estimations without controls. In columns 2, 4 and 6 we include controls for important individual characteristics such as gender, age, and intelligence, as well as occupation of the parents. The signs of the coefficients of interest are identical to the preschool sample. Longer breastfeeding duration is statistically significantly associated with less willingness to take risk and higher levels of patience and altruism. As before, all effects are robust to including a set of controls. In terms of effect size the coefficients of the two samples are difficult to compare due to different sample compositions and elicitation techniques. However, concerning risk preferences where we use ratio scale measures in both samples, effect sizes are moderately bigger for the young adults than for the preschoolers. This suggests an increasing impact of early childhood environment within the development process and is in line with a self-productive and dynamic complementary pattern of production functions as suggested by Cunha and Heckman (2007). The fact that we are able to replicate the same preference pattern in response to breastfeeding duration for young adults, further suggests that social environment at early childhood has an enduring and persistent impact on the development of preferences.

\subsubsection{Disentangling nutritional and environmental effects}

As shown in section 2, breastfeeding duration proxies a broad range of aspects of a positive early childhood environment. For the given data structure it is not possible to completely decompose the specific effects of these aspects. However, in the context of breastfeeding it is of special interest if the documented pattern is purely driven by direct nutritional effects. ${ }^{22}$ If this were the case, this would restrict our interpretation of the documented pattern.

To disentangle nutritional from general social environment-related effects, we compare breastfed to non-breastfed individuals. The physiological literature suggests that the nutritional benefits of breastfeeding should have monotonic effects (Butte et al., 2002; Koletzko et al., 2001). This means a long duration should have a stronger effect than a short duration and a short duration should have a stronger effect than not being breastfed at all. ${ }^{23}$ Therefore, if the relations shown in Table 2 were driven by purely nutritional effects, breastfed individuals should be more patient, risk averse and altruistic than non-breastfed individuals. In contrast, if non-nutritional environmental factors drive the effects, non-breastfed individuals should be similar to average breastfed individuals, since the pattern of parent-child interactions of

\footnotetext{
${ }^{22}$ Breast milk contains unique nutritious components, at which, especially long-chain saturated fatty acids are suggested to be important for brain development (Uauy and De Andraca, 1995; Koletzko et al., 2001).

${ }^{23}$ This should especially hold true for the here considered durations of mostly less than 12 months.
} 
breastfed and non-breastfed individuals does not differ (see Wald-test in Table 1). Therefore, comparing preferences of breastfed and non-breastfed individuals provides insights into the nutritional impact of breastfeeding on preference formation.

The means of time, risk, and social preference measures of breastfed and nonbreastfed children and adults are displayed in Figure A2. Mean comparisons of breastfed and non-breastfed individuals reveal no statistically significant differences. There is also no indication of a difference between breastfed and non-breastfed individuals when testing the six hypotheses ${ }^{24}$ of no difference in means jointly $(p=$ $\left.0.552, \chi^{2}(6)=4.94, N=596\right)$. These findings contradict the interpretation of a purely nutritional impact of breastfeeding on preference formation and supports our interpretation that breastfeeding duration proxies a wide range of positive social environmental factors.

\section{Discussion and Conclusion}

We have validated breastfeeding duration (conditional on being breastfed at all) as a measure of the quality of early childhood environment. This offers a great potential since mothers remember breastfeeding durations in a valid and reliable way (Li et al., 2005). Therefore, information about breastfeeding duration is accessible in retrospect, enabling researchers to explore the effect of early childhood environment in various independent samples covering different age cohorts and outcomes. The question if breastfeeding duration validly proxies early childhood environment in a given context needs to be discussed in the particular case. Our validation was conducted using the birth cohorts 2004-2007 in Germany. Drawing from sociological literature we believe that the validation holds for most industrialized western societies and birth cohorts from the 1990s onwards (Faircloth, 2014; Heimerdinger, 2009). Breastfeeding patterns and parenting cultures have been relatively stable in this context and period. Recent evidence on the relation between breastfeeding duration and IQ, based on Brazilian data, regarding birth cohorts from the early 1980s, suggests that our interpretation might be transferable to even further cohorts and (parenting) cultures (Kosse, 2016)..$^{25}$

In the main analysis, we have explored the role of the quality of early childhood environment concerning the formation of preferences using two independent data

\footnotetext{
${ }^{24}$ The six hypothesis regard differences in time, risk and social preferences of preschool children as well as young adults, respectively.

${ }^{25}$ In line with the analysis in section 3.3.2. Kosse (2016) shows that the correlation between breastfeeding duration and IQ is mainly driven by social environment-related factors rather than nutritional effects.
} 
sets, varying by age of participants (preschool children vs. young adults). We find a robust, systematic and persistent relation between breastfeeding duration and time, risk and social preferences. Comparing breastfed and non-breastfed individuals indicates that the observed pattern is driven by general positive social environmental rather than purely nutritional factors. Conditioning on parental socio-economic status and preferences, our results suggest that early childhood environment, above and beyond purely intellectual or monetary resources, are crucial determinants for the development of preferences.

Important questions arising from our main findings are how to interpret the observed preference pattern and how the effects of early childhood environment on preferences translate into real-life behavior. Previous work has shown positive behavioral and health outcomes for more patient, risk averse and altruistic individuals (Sutter et al., 2013; Becker et al., 2012; Ida and Goto, 2009). In light of these findings we hypothesized that individuals grown-up in higher quality early childhood environments should, in response to higher levels of patience and altruism as well as a lower willingness to take risk, more often forgo immediate pleasurable, risky, and antisocial behavior as, e.g., underage drinking. In fact, using data of the German Health Survey for Children and Adolescents (KiGGS, 2008) we find evidence in support of this hypothesis. Analyzing the underage drinking behavior of about 4400 adolescents indicates a lower probability of underage drinking for children who have been breastfed longer (see Table A7). As for the preference measures the relation is robust controlling for parental SES and we provide evidence against direct nutritional effects of breastfeeding (see discussion in section 3.3.2). These findings suggest that preferences that are affected by the early childhood environment serve as important channels for the transmission of early childhood environment into behavior and life outcomes.

In general, documenting the relation between the early environment and preferences suggests that findings on human capital and non-cognitive skills explicitly extend to key economic preferences (Cunha and Heckman, 2007; Currie and Almond, 2011) and verifies frequently posed assumptions on the malleability of preferences (Becker and Mulligan, 1997; Doepke and Zilibotti, 2008, 2012). 


\section{References}

Ainsworth, M. S. and Bowlby, J. (1991), 'An ethological approach to personality development.', American Psychologist 46(4), 333-341.

Alan, S., Baydar, N., Boneva, T., Ertac, S. and Crossley, T. F. (2014), 'Parental socialization effort and the intergenerational transmission of risk preferences', SSRN 2566409 .

Almås, I., Cappelen, A. W., Salvanes, K. G., Sørensen, E. Ø. and Tungodden, B. (2015), 'Willingness to compete: Family matters', Management Science 62, 21492162.

Almås, I., Cappelen, A. W., Salvanes, K. G., Sørensen, E. Ø. and Tungodden, B. (2016), 'Fairness and family background', Politics, Philosophy $\& 6$ Economics .

Almås, I., Cappelen, A. W., Sørensen, E. Ø. and Tungodden, B. (2010), 'Fairness and the development of inequality acceptance', Science 328(5982), 1176-1178.

Angerer, S., Glätzle-Rützler, D., Lergetporer, P. and Sutter, M. (2016), 'Cooperation and discrimination within and across language borders: Evidence from children in a bilingual city', European Economic Review 90, 254-264.

Bartling, B., Fehr, E., Fischer, B., Kosse, F., Maréchal, M., Pfeiffer, F., Schunk, D., Schupp, J., Spieß, C. K. and Wagner, G. G. (2010), 'Determinanten kindlicher Geduld - Ergebnisse einer Experimentalstudie im Haushaltskontext', Schmollers Jahrbuch: Journal of Applied Social Science Studies 130, 297-323.

Bartling, B., Fehr, E., Maréchal, M. A. and Schunk, D. (2009), 'Egalitarianism and competitiveness', The American Economic Review 99(2), 93-98.

Bauer, M., Chytilová, J. and Pertold-Gebicka, B. (2014), 'Parental background and other-regarding preferences in children', Experimental Economics 17(1), 24-46.

Becker, A., Deckers, T., Dohmen, T., Falk, A. and Kosse, F. (2012), 'The relationship between economic preferences and psychological personality measures', Annual Review of Economics 4(1), 453-478.

Becker, G. S. and Mulligan, C. B. (1997), 'The endogenous determination of time preference', The Quarterly Journal of Economics 112(3), 729-758. 
Benjamin, D. J., Cesarini, D., van der Loos, M. J., Dawes, C. T., Koellinger, P. D., Magnusson, P. K., Chabris, C. F., Conley, D., Laibson, D., Johannesson, M. et al. (2012), 'The genetic architecture of economic and political preferences', Proceedings of the National Academy of Sciences 109(21), 8026-8031.

Black, S. E., Devereux, P. J. and Salvanes, K. G. (2009), 'Like father, like son? a note on the intergenerational transmission of iq scores', Economics Letters 105(1), 138140.

Blomeyer, D., Coneus, K., Laucht, M. and Pfeiffer, F. (2009), 'Initial risk matrix, home resources, ability development, and children's achievement', Journal of the European Economic Association 7(2-3), 638-648.

Bradley, R. H. and Caldwell, B. M. (1980), 'The relation of home environment, cognitive competence, and iq among males and females', Child Development pp. 11401148.

Burks, S. V., Carpenter, J. P., Goette, L. and Rustichini, A. (2009), 'Cognitive skills affect economic preferences, strategic behavior, and job attachment', Proceedings of the National Academy of Sciences 106(19), 7745-7750.

Butte, N. F., Lopez-Alarcon, M. G. and Garza, C. (2002), Nutrient adequacy of exclusive breastfeeding for the term infant during the first six months of life, Geneva: World Health Organization.

Cesarini, D., Dawes, C. T., Johannesson, M., Lichtenstein, P. and Wallace, B. (2009), 'Genetic variation in preferences for giving and risk taking', The Quarterly Journal of Economics 124(2), 809-842.

Chabris, C. F., Laibson, D., Morris, C. L., Schuldt, J. P. and Taubinsky, D. (2008), 'Individual laboratory-measured discount rates predict field behavior', Journal of Risk and Uncertainty 37(2-3), 237-269.

Chen, A. and Rogan, W. J. (2004), 'Breastfeeding and the risk of postneonatal death in the United States', Pediatrics 113(5), 435-439.

Chen, M. K. (2013), 'The effect of language on economic behavior: Evidence from savings rates, health behaviors, and retirement assets', The American Economic Review 103(2), 690-731.

Croson, R. and Gneezy, U. (2009), 'Gender differences in preferences', Journal of Economic literature pp. 448-474. 
Culhane, J., Cunha, F., Elo, I. and Pham, Z. (2016), 'Measuring early investments in children', Mimeo .

Cunha, F. and Heckman, J. (2007), 'The technology of skill formation', American Economic Review 97(2), 31-47.

Cunha, F. and Heckman, J. J. (2008), 'Formulating, identifying and estimating the technology of cognitive and noncognitive skill formation', Journal of Human Resources 43(4), 738-782.

Cunha, F., Heckman, J. J. and Schennach, S. M. (2010), 'Estimating the technology of cognitive and noncognitive skill formation', Econometrica 78(3), 883-931.

Currie, J. and Almond, D. (2011), Human capital development before age five, in O. Ashenfelter and D. Card, eds, 'Handbook of Labor Economics', Vol. 4 B, Elsevier, pp. 1315-1486.

Currie, J. and Moretti, E. (2003), 'Mother's education and the intergenerational transmission of human capital: Evidence from college openings', The Quarterly Journal of Economics 118(4), 1495-1532.

Del Bono, E. and Rabe, B. (2012), 'Breastfeeding and child cognitive outcomes: Evidence from a hospital-based breastfeeding support policy', ESRC Working Paper 2012-29.

Doepke, M. and Zilibotti, F. (2008), 'Occupational choice and the spirit of capitalism', The Quarterly Journal of Economics 123(2), 747-793.

Doepke, M. and Zilibotti, F. (2012), 'Parenting with style: Altruism and paternalism in intergenerational preference transmission', IZA Discussion Paper Series $\mathbf{7 1 0 8 .}$

Dohmen, T., Falk, A., Huffman, D. and Sunde, U. (2010), 'Are risk aversion and impatience related to cognitive ability?', The American Economic Review $\mathbf{1 0 0}(3), 1238-1260$.

Dohmen, T., Falk, A., Huffman, D. and Sunde, U. (2012), 'The intergenerational transmission of risk and trust attitudes', The Review of Economic Studies $\mathbf{7 9}(2), 645-677$.

Dohmen, T., Falk, A., Huffman, D., Sunde, U., Schupp, J. and Wagner, G. G. (2011), 'Individual risk attitudes: Measurement, determinants, and behavioral consequences', Journal of the European Economic Association 9(3), 522-550. 
Eckel, C. C. and Grossman, P. J. (1996), 'Altruism in anonymous dictator games', Games and Economic Behavior 16(2), 181-191.

Faircloth, C. (2014), Intensive parenting and the expansion of parenting, in E. Lee, J. Bristow and C. Faircloth, eds, 'Parenting Culture Studies', Palgrave MacMillan, pp. 25-50.

Fehr, E., Bernhard, H. and Rockenbach, B. (2008), 'Egalitarianism in young children', Nature 454(7208), 1079-1083.

Fehr, E. and Fischbacher, U. (2003), 'The nature of human altruism', Nature 425(6960), 785-791.

Fehr, E., Glätzle-Rützler, D. and Sutter, M. (2013), 'The development of egalitarianism, altruism, spite and parochialism in childhood and adolescence', European Economic Review 64, 369-383.

Fischbacher, U. (2007), 'z-tree: Zurich toolbox for ready-made economic experiments', Experimental Economics 10(2), 171-178.

Frederick, S., Loewenstein, G. and O'Donoghue, T. (2002), 'Time discounting and time preference: A critical review', Journal of Economic Literature 40(2), 351-401.

Greiner, B. (2004), 'An online recruitment system for economic experiments', Forschung und wissenschaftliches Rechnen 63, 79-93.

Heimerdinger, T. (2009), Brust oder Flasche? - Säuglingsernährung und die Rolle von Beratungsmedien, in M. Simon, T. Hengartner, T. Heimerdinger and A. Lux, eds, 'Bilder. Bücher. Bytes', Waxmann: Münster, pp. 100-110.

Heinrichs, M., Neumann, I. and Ehlert, U. (2002), 'Lactation and stress: Protective effects of breast-feeding in humans', Stress: The International Journal on the Biology of Stress 5(3), 195-203.

Ida, T. and Goto, R. (2009), 'Interdependency among addictive behaviours and time/risk preferences: Discrete choice model analysis of smoking, drinking, and gambling', Journal of Economic Psychology 30(4), 608-621.

Jaeger, D. A., Dohmen, T., Falk, A., Huffman, D., Sunde, U. and Bonin, H. (2010), 'Direct evidence on risk attitudes and migration', The Review of Economics and Statistics 92(3), 684-689. 
Jayachandran, S. and Kuziemko, I. (2011), 'Why do mothers breastfeed girls less than boys? evidence and implications for child health in india', The Quarterly Journal of Economics 126(3), 1485-1538.

KiGGS (2008), 'German Health Survey for Children and Adolescents, Robert Koch Institute, Berlin'.

Koletzko, B., Agostoni, C., Carlson, S., Clandinin, T., Hornstra, G., Neuringer, M., Uauy, R., Yamashiro, Y. and Willatts, P. (2001), 'Long chain polyunsaturated fatty acids (LC-PUFA) and perinatal development', Acta Paediatrica 90(4), 460464.

Kosse, F. (2016), 'The nutritional and social environment-related effects of breastfeeding on intelligence', JAMA Pediatrics 170(2), 173-174.

Kosse, F. and Pfeiffer, F. (2012), 'Impatience among preschool children and their mothers', Economics Letters 115(3), 493-495.

Lang, F. R., Hahne, D., Gymbel, S., Schröpper, S. and Lutsch, K. (2005), 'Erfassung des kognitiven Leistungspotenzials und der "Big Five" mit Computer-AssistedPersonal-Interviewing (CAPI): Zur Reliabilität und Validität zweier ultrakurzer Tests und des BFI-S', DIW Research Notes $\mathbf{9}$.

Lang, F. R., Weiss, D., Stocker, A. and von Rosenbladt, B. (2007), 'Assessing cognitive capacities in computer-assisted survey research: Two ultra-short tests of intellectual ability in the German Socio-Economic Panel (SOEP)', Schmollers Jahrbuch: Journal of Applied Social Science Studies 127(1), 183-192.

Li, R., Scanlon, K. S. and Serdula, M. K. (2005), 'The validity and reliability of maternal recall of breastfeeding practice', Nutrition Reviews 63(4), 103-110.

Mischel, W., Shoda, Y. and Rodriguez, M. I. (1989), 'Delay of gratification in children', Science 244(4907), 933-938.

Mortensen, E. L. (2015), 'Life course consequences of breastfeeding', The Lancet Global Health 3(4), e179-e180.

Slovic, P. (1966), 'Risk-taking in children: Age and sex differences', Child Development pp. 169-176.

SOEP (2012), 'German Socio-Economic Panel, data for years 1984-2011, version 28, doi:10.5684/soep.v28'. 
Spinath, B., Spinath, F. M., Harlaar, N. and Plomin, R. (2006), 'Predicting school achievement from general cognitive ability, self-perceived ability, and intrinsic value', Intelligence 34(4), 363-374.

Sutter, M. and Glätzle-Rützler, D. (2015), 'Gender differences in the willingness to compete emerge early in life and persist', Management Science 61(10), 233923354 .

Sutter, M., Kocher, M. G., Glätzle-Rützler, D. and Trautmann, S. T. (2013), 'Impatience and uncertainty: Experimental decisions predict adolescents' field behavior', The American Economic Review 103(1), 510-531.

Tewes, U. (1994), Hamburg Wechsler Test für Erwachsene (HAWIE-R), Bern: Huber.

Todd, P. E. and Wolpin, K. I. (2007), 'The production of cognitive achievement in children: Home, school, and racial test score gaps', Journal of Human capital 1(1), 91-136.

Uauy, R. and De Andraca, I. (1995), 'Human milk and breast feeding for optimal mental development', Journal of Nutrition 125(8), 2278S.

Wagner, G. G., Frick, J. R. and Schupp, J. (2007), 'The German Socio-Economic Panel Study (SOEP) - Scope, Evolution and Enhancements', Schmollers Jahrbuch: Journal of Applied Social Science Studies 127(1), 139-169.

Weiss, R. (2006), Grundintelligenztest (CFT 20-R), Goettingen: Hogrefe. 


\section{Appendix}

\section{Additional Tables and Figures}

\begin{tabular}{llll}
\hline Name of dataset & $\begin{array}{l}\text { Source of BF } \\
\text { information }\end{array}$ & Other available info & Used in \\
\hline SOEP & current & $\begin{array}{l}\text { Time spending, maternal health } \\
\text { and happiness, SES }\end{array}$ & $\begin{array}{l}\text { Table 1, A2, A3, } \\
\text { Figure A1 }\end{array}$ \\
\hline MARS & current & HOME inventory & Table A3 \\
\hline Preschool sample & retrospect & $\begin{array}{l}\text { Preference measures at preschool } \\
\text { age }\end{array}$ & Table 2, A4, A5, \\
\hline Young adult sample & retrospect & $\begin{array}{l}\text { Preference measures in the early } \\
\text { 20s }\end{array}$ & Table 2, A6 \\
\hline KiGGS & & Underage drinking behavior in & Table A7 \\
& retrospect & adolescence & \\
\hline
\end{tabular}

Table A1: Overview over available information in the used datasets. SOEP (German SocioEconomic Panel) and MARS (Mannheim Study of Children at Risk) are used for the validation in section 2. Preschool and young adults samples are used in the main analysis in section 3. KiGGS (German Health Survey for Children and Adolescents) data is used to analyze the relation between early life circumstances and underage drinking in section 4 . 


\begin{tabular}{lccc}
\hline & \multicolumn{3}{c}{ Rotated } \\
& $\begin{array}{c}\text { Hingh } \\
\text { quality } \\
\text { time }\end{array}$ & $\begin{array}{c}\text { Medium } \\
\text { quality } \\
\text { time }\end{array}$ & $\begin{array}{c}\text { Low } \\
\text { quality } \\
\text { time }\end{array}$ \\
\hline How many times in the last 14 days have you or the & & & \\
main caregiver done the following activities together & & & \\
with your child? & & & \\
Singing children's songs with or to the child & $\mathbf{0 . 4 4 4 3}$ & -0.0034 & -0.1241 \\
Reading or telling stories & $\mathbf{0 . 5 7 8 7}$ & -0.0178 & -0.1144 \\
Looking at picture books & $\mathbf{0 . 5 5 7 6}$ & -0.0496 & -0.0090 \\
Painting or doing arts and crafts & 0.3475 & 0.1182 & 0.3454 \\
Taking walks outdoors & 0.1022 & $\mathbf{0 . 4 2 6 9}$ & 0.1194 \\
Going to the playground & 0.011 & $\mathbf{0 . 5 4 6 4}$ & 0.0019 \\
Visiting other families with children & -0.0336 & $\mathbf{0 . 5 6 0 2}$ & -0.2454 \\
Going shopping with the child & -0.1521 & $\mathbf{0 . 4 3 7 5}$ & 0.0513 \\
Watching television or videos with the child & -0.0799 & -0.085 & $\mathbf{0 . 8 8 7 9}$ \\
\hline
\end{tabular}

Table A2: Principal component analysis concerning the quality of the parent-child interaction (age 2-3 years). Source: $\operatorname{SOEP}(2012) ; N=552$; Mothers are asked how many times in the last 14 days she, or the main caregiver, has done particular activities together with their child. Using the answers concerning all nine potential activities we performed a principal component analysis (rotation method: Oblique promax (power $=3$ ), resulting in three components according to Kaiser Criterion (Eigenvalue $>1$ ). The first component reflects activities, which involve face-to-face contact and a high degree of interaction between mother and child such as reading or telling children's stories or singing children's songs with the child (high quality time). The second component reflects activities with a medium degree of interaction and less direct contact such as going shopping or visiting other families with the child (medium quality time). The third component represents watching TV or videos (low quality time).

\begin{tabular}{|c|c|c|}
\hline Correlations between breastfeeding duration and ... & $\begin{array}{l}\text { Spearman's } \\
\text { rho }\end{array}$ & $p$-value \\
\hline HOME inventory (at age: 2 years) ${ }^{\mathrm{a}}$ & 0.177 & 0.003 \\
\hline Importance of having children for mother ${ }^{\mathrm{b}}$ & 0.111 & 0.015 \\
\hline Life satisfaction of the mother (in the year of birth of the child) ${ }^{b}$ & 0.099 & 0.030 \\
\hline
\end{tabular}

Table A3: Correlations of breastfeeding duration and other variables reflecting the quality of early life circumstances. Sources: ${ }^{a}$ Mannheim Study of Children at Risk (MARS) (Blomeyer et al., 2009) $(N=384)$ and ${ }^{\mathrm{b}}$ SOEP $(2012)(N=484)$, samples are restricted to breastfed children. We acknowledge provision of correlations concerning HOME Inventory by Friedhelm Pfeiffer. Displayed coefficients are Spearman rank correlation coefficients. Home Observation for Measurement of the Environment (HOME) (Bradley and Caldwell, 1980; Blomeyer et al., 2009) is a 26 item rating. Importance of having children is measured on a 4-point scale in the year 2008 when all children were already born. Life satisfaction of the mother is measured in the year of birth of the child and is measured on an 11-point Likert scale. 


\begin{tabular}{|c|c|c|c|c|c|c|}
\hline & \multicolumn{2}{|c|}{$\begin{array}{l}\text { Time }(0 / 1) \\
\text { Probit }\end{array}$} & \multicolumn{2}{|c|}{$\begin{array}{c}\text { Risk (standardized) } \\
\text { OLS }\end{array}$} & \multicolumn{2}{|c|}{$\begin{array}{l}\text { Altruism }(0 / 1) \\
\text { Probit }\end{array}$} \\
\hline & (1) & $(2)$ & $(3)$ & $(4)$ & $(5)$ & $(6)$ \\
\hline \multicolumn{7}{|l|}{ Breastfeeding } \\
\hline $\begin{array}{l}\text { Duration of breastfeeding } \\
\text { (in months) }\end{array}$ & $\begin{array}{l}0.023^{* * *} \\
(0.008)\end{array}$ & $\begin{array}{c}0.024^{* * *} \\
(0.008)\end{array}$ & $\begin{array}{c}-0.032^{* *} \\
(0.016)\end{array}$ & $\begin{array}{c}-0.029^{*} \\
(0.017)\end{array}$ & $\begin{array}{l}0.016^{* *} \\
(0.007)\end{array}$ & $\begin{array}{c}0.017^{* * *} \\
(0.006)\end{array}$ \\
\hline \multicolumn{7}{|l|}{ Child's characteristics } \\
\hline Age (in months) & & $\begin{array}{c}0.004 \\
(0.005)\end{array}$ & & $\begin{array}{c}0.012 \\
(0.020)\end{array}$ & & $\begin{array}{l}-0.000 \\
(0.008)\end{array}$ \\
\hline Dummy male & & $\begin{array}{c}0.041 \\
(0.056)\end{array}$ & & $\begin{array}{l}0.550^{* * *} \\
(0.181)\end{array}$ & & $\begin{array}{c}0.007 \\
(0.059)\end{array}$ \\
\hline Height (in $10 \mathrm{~cm}$ ) & & $\begin{array}{c}0.034 \\
(0.040)\end{array}$ & & $\begin{array}{l}-0.232 \\
(0.199)\end{array}$ & & $\begin{array}{l}0.117^{* *} \\
(0.054)\end{array}$ \\
\hline Intelligence (standardized) & & $\begin{array}{c}0.042 \\
(0.030)\end{array}$ & & $\begin{array}{l}0.035 \\
(0.150)\end{array}$ & & $\begin{array}{l}-0.000 \\
(0.050)\end{array}$ \\
\hline Dummy older siblings & & $\begin{array}{c}0.024 \\
(0.064)\end{array}$ & & $\begin{array}{l}-0.013 \\
(0.211)\end{array}$ & & $\begin{array}{l}0.015 \\
(0.073)\end{array}$ \\
\hline Dummy younger siblings & & $\begin{array}{c}0.077 \\
(0.073)\end{array}$ & & $\begin{array}{c}0.077 \\
(0.212)\end{array}$ & & $\begin{array}{c}0.037 \\
(0.070)\end{array}$ \\
\hline Parental SES & & & & & & \\
\hline College degree mother & & $\begin{array}{l}-0.063 \\
(0.082)\end{array}$ & & $\begin{array}{l}-0.083 \\
(0.224)\end{array}$ & & $\begin{array}{c}0.038 \\
(0.072)\end{array}$ \\
\hline Log net household income & & $\begin{array}{l}-0.062 \\
(0.066)\end{array}$ & & $\begin{array}{l}0.019 \\
(0.253)\end{array}$ & & $\begin{array}{c}0.042 \\
(0.069)\end{array}$ \\
\hline Preferences \& IQ of mo & & & & & & \\
\hline Intelligence & & $\begin{array}{l}-0.026 \\
(0.030)\end{array}$ & & $\begin{array}{l}-0.148 \\
(0.120)\end{array}$ & & $\begin{array}{l}-0.025 \\
(0.042)\end{array}$ \\
\hline Time preference & & $\begin{array}{c}0.065^{* *} \\
(0.030)\end{array}$ & & & & \\
\hline Risk preference & & & & $\begin{array}{l}-0.097 \\
(0.096)\end{array}$ & & \\
\hline Altruism & & & & & & $\begin{array}{c}0.113 \\
(0.111)\end{array}$ \\
\hline Task specific controls & yes & yes & no & no & yes & yes \\
\hline $\begin{array}{l}\text { Observations } \\
\text { (Pseudo) } R \text {-squared }\end{array}$ & $\begin{array}{c}198 \\
0.066\end{array}$ & $\begin{array}{c}198 \\
0.157\end{array}$ & $\begin{array}{c}109 \\
0.024\end{array}$ & $\begin{array}{c}109 \\
0.142\end{array}$ & $\begin{array}{c}101 \\
0.090\end{array}$ & $\begin{array}{c}101 \\
0.185\end{array}$ \\
\hline
\end{tabular}

Table A4: The effect of quality of early childhood environment on preschool children's preferences. Displayed coefficients are average marginal effects with respective preference as dependent variable. In the estimations we use age and age squared of the child as explanatory variables. The combined intelligence measure of the child is the standardized score of standardized fluid and crystallized intelligence. The variable "net monthly household income" refers to the current monthly income of all household members, net of taxes and benefits. For less than 20 percent of respondents, income was only reported in intervals $(<750 ; 750-1,500 ; 1,500-2,500 ; 2,500-3,500 ; 3,500-5,000 ;>5,000$ Euros). In these cases we used the interval midpoints (7,500 in case of income exceeding 5,000$)$. All preference and IQ measures of the mother are standardized, the only exception is altruism which is a dummy indicating selecting the altruistic distribution. Intelligence of the mother is measured by the number of correct answers in a symbol-digit-test. Time preference of mothers' is the (reversed) switching row in the time preference choice task, risk preference is the certainty equivalent in the lottery task. Task specific controls in columns $1 / 2$ are dummies indicating elapsed time since the last bigger meal and in columns $5 / 6$ dummies indicating if the receiver is from the same kindergarten and the sequence of distribution games. To receive comparable results we exclude observations with missing values in the covariates from all regressions. Robust standard errors in parentheses. ${ }^{* * *},{ }^{* *},{ }^{*}$ indicate significance at $1-, 5$-, and 10-percent level, respectively. 


\begin{tabular}{lcccccc}
\hline & \multicolumn{2}{c}{ Time (0/1) } & \multicolumn{2}{c}{ Risk (standardized) } & \multicolumn{2}{c}{ Altruism (0/1) } \\
& \multicolumn{2}{c}{ Probit } & \multicolumn{2}{c}{ OLS } & \multicolumn{2}{c}{ Probit } \\
& $(1)$ & $(2)$ & $(3)$ & $(4)$ & $(5)$ & $(6)$ \\
\hline Breastfeeding & & & & & & \\
$\begin{array}{l}\text { Duration of breastfeeding } \\
\text { (in months) }\end{array}$ & $0.024^{* * *}$ & $0.023^{* * *}$ & $-0.032^{* *}$ & $-0.032^{* *}$ & $0.016^{* *}$ & $0.016^{* *}$ \\
Sample restriction & $(0.007)$ & $(0.008)$ & $(0.016)$ & $(0.016)$ & $(0.007)$ & $(0.007)$ \\
Observations & No & Yes & No & Yes & No & Yes \\
(Pseudo) R-squared & 222 & 198 & 111 & 109 & 103 & 101 \\
\hline
\end{tabular}

Table A5: The effect of quality of childhood environment on preferences of preschool children using different sample restrictions. In columns 2, 4 and 6 the sample it restricted to observations without missing values in the covariates used in Table A4. The estimations in columns $1 / 2$ include dummies indicating elapsed time since the last bigger meal. The estimations in columns $5 / 6$ include dummies indicating if the receiver is from the same kindergarten and the sequence of distribution games. Displayed coefficients are average marginal effects with respective preference as dependent variable and robust standard errors in parentheses. ${ }^{* * *},{ }^{* *},{ }^{*}$ indicate significance at $1-, 5-$, and 10-percent level, respectively.

\begin{tabular}{|c|c|c|c|c|c|c|}
\hline & \multicolumn{2}{|c|}{$\begin{array}{l}\text { Time (std.) } \\
\text { OLS }\end{array}$} & \multicolumn{2}{|c|}{$\begin{array}{l}\text { Risk (std.) } \\
\text { OLS }\end{array}$} & \multicolumn{2}{|c|}{$\begin{array}{c}\text { Altruism (std.) } \\
\text { OLS }\end{array}$} \\
\hline & (1) & (2) & (3) & (4) & (5) & $(6)$ \\
\hline \multicolumn{7}{|l|}{ Breastfeeding } \\
\hline $\begin{array}{l}\text { Duration of breastfeeding } \\
\text { (in months) }\end{array}$ & $\begin{array}{l}0.041^{* *} \\
(0.016)\end{array}$ & $\begin{array}{l}0.037^{* *} \\
(0.016)\end{array}$ & $\begin{array}{r}-0.037^{*} \\
(0.021)\end{array}$ & $\begin{array}{c}-0.041^{* *} \\
(0.019)\end{array}$ & $\begin{array}{l}0.048^{* * *} \\
(0.016)\end{array}$ & $\begin{array}{l}0.045^{* * *} \\
(0.015)\end{array}$ \\
\hline \multicolumn{7}{|l|}{ Child's characteristics } \\
\hline Age (in months) & & $\begin{array}{l}-0.030 \\
(0.033)\end{array}$ & & $\begin{array}{c}0.030 \\
(0.035)\end{array}$ & & $\begin{array}{l}0.056^{*} \\
(0.033)\end{array}$ \\
\hline Dummy male & & $\begin{array}{l}0.151 \\
(0.157)\end{array}$ & & $\begin{array}{c}0.033 \\
(0.162)\end{array}$ & & $\begin{array}{l}-0.036 \\
(0.160)\end{array}$ \\
\hline $\begin{array}{l}\text { High school math grade } \\
\text { (low is better) }\end{array}$ & & $\begin{array}{l}-0.136^{*} \\
(0.069)\end{array}$ & & $\begin{array}{l}-0.039 \\
(0.078)\end{array}$ & & $\begin{array}{l}-0.079 \\
(0.068)\end{array}$ \\
\hline Parental SES & & & & & & \\
\hline Occupation of father (dummies) & No & $\mathrm{Yes}^{++}$ & No & $\mathrm{Yes}^{++}$ & No & Yes $^{+}$ \\
\hline Occupation of mother (dummies) & No & $\mathrm{Yes}^{+}$ & No & Yes $^{+}$ & No & Yes \\
\hline Observations & 175 & 175 & 175 & 175 & 175 & 175 \\
\hline R-squared & 0.028 & 0.222 & 0.021 & 0.210 & 0.037 & 0.165 \\
\hline
\end{tabular}

Table A6: The effect of quality of childhood environment on young adults' preferences. Displayed coefficients are marginal effects, with respective standardized preference measure as dependent variable and robust standard errors in parentheses. In the estimations we use age and age squared of the young adult as explanatory variables. High school math grade serves as a proxy for IQ and is coded in the typical German 6-point grading system where lower values indicate better performance. Parental SES is controlled for by including dummies indicating occupations of father and mother. ${ }^{* * *},{ }^{* *},{ }^{*}$ indicate significance at $1-, 5$-, and 10 -percent level, respectively. ${ }^{+++},{ }^{++}$, + indicate significance at 1-, 5-, and 10-percent level of Wald-tests testing the hypothesis that all coefficients of the respective category are zero. 
(1)

(2)

(3)

(4)

\begin{tabular}{|c|c|c|c|c|}
\hline $\begin{array}{l}\text { Breastfeeding duration } \\
\text { (in months) }\end{array}$ & $\begin{array}{c}-0.008^{* * *} \\
(0.002)\end{array}$ & $\begin{array}{c}-0.005^{* * *} \\
(0.002)\end{array}$ & & \\
\hline Breastfed dummy (1 = yes $)$ & & & $\begin{array}{c}-0.020 \\
(0.017)\end{array}$ & $\begin{array}{c}-0.017 \\
(0.015)\end{array}$ \\
\hline Age (in years) & & $\begin{array}{c}0.161^{* * *} \\
(0.003)\end{array}$ & & $\begin{array}{c}0.161^{* * *} \\
(0.003)\end{array}$ \\
\hline Dummy male & & $\begin{array}{c}0.002 \\
(0.015)\end{array}$ & & $\begin{array}{c}0.006 \\
(0.013)\end{array}$ \\
\hline College degree mother & & $\begin{array}{l}-0.013 \\
(0.020)\end{array}$ & & $\begin{array}{l}-0.001 \\
(0.018)\end{array}$ \\
\hline Log net $\mathrm{HH}$ income & & $\begin{array}{l}0.036^{* *} \\
(0.015)\end{array}$ & & $\begin{array}{c}0.016 \\
(0.013)\end{array}$ \\
\hline Sample restriction & $\mathrm{BF}>0$ & $\mathrm{BF}>0$ & None & None \\
\hline Observations & 3,260 & 3,260 & 4,401 & 4,401 \\
\hline Pseudo R-squared & 0.004 & 0.220 & 0.0002 & 0.215 \\
\hline
\end{tabular}

Table A7: The effect of the quality of early childhood environment on underage drinking behavior. Source: KiGGS (2008). We analyze underage drinking behavior of about 4400 adolescents at the age of 11 to 15 years. Note: Before the age of 16 years it is not allowed to buy alcoholic drinks in Germany. Information regarding breastfeeding were provided by the mothers, information regarding alcohol consumption are self-reports by the adolescents. As hypothesized, column 1 reveals that breastfeeding duration is negatively associated with the probability of underage drinking. Conditioning on parental socio-economic status and individual characteristics, column 2 reveals a smaller but still significant conditional correlation in the hypothesized direction. As for the preference measures, comparing breastfed and non-breastfed children indicates no statistically significant differences in underage drinking behavior (columns 3 and 4), which provides further evidence on an effect of the general quality of childhood environment in contrast to a nutritional effect related to breastfeeding. Displayed coefficients are average marginal effects with robust standard errors in parentheses. In the estimations we use age and age squared as explanatory variables. ${ }^{* * *},{ }^{* *},{ }^{*}$ indicate significance at 1-, 5-, and 10-percent level, respectively. 


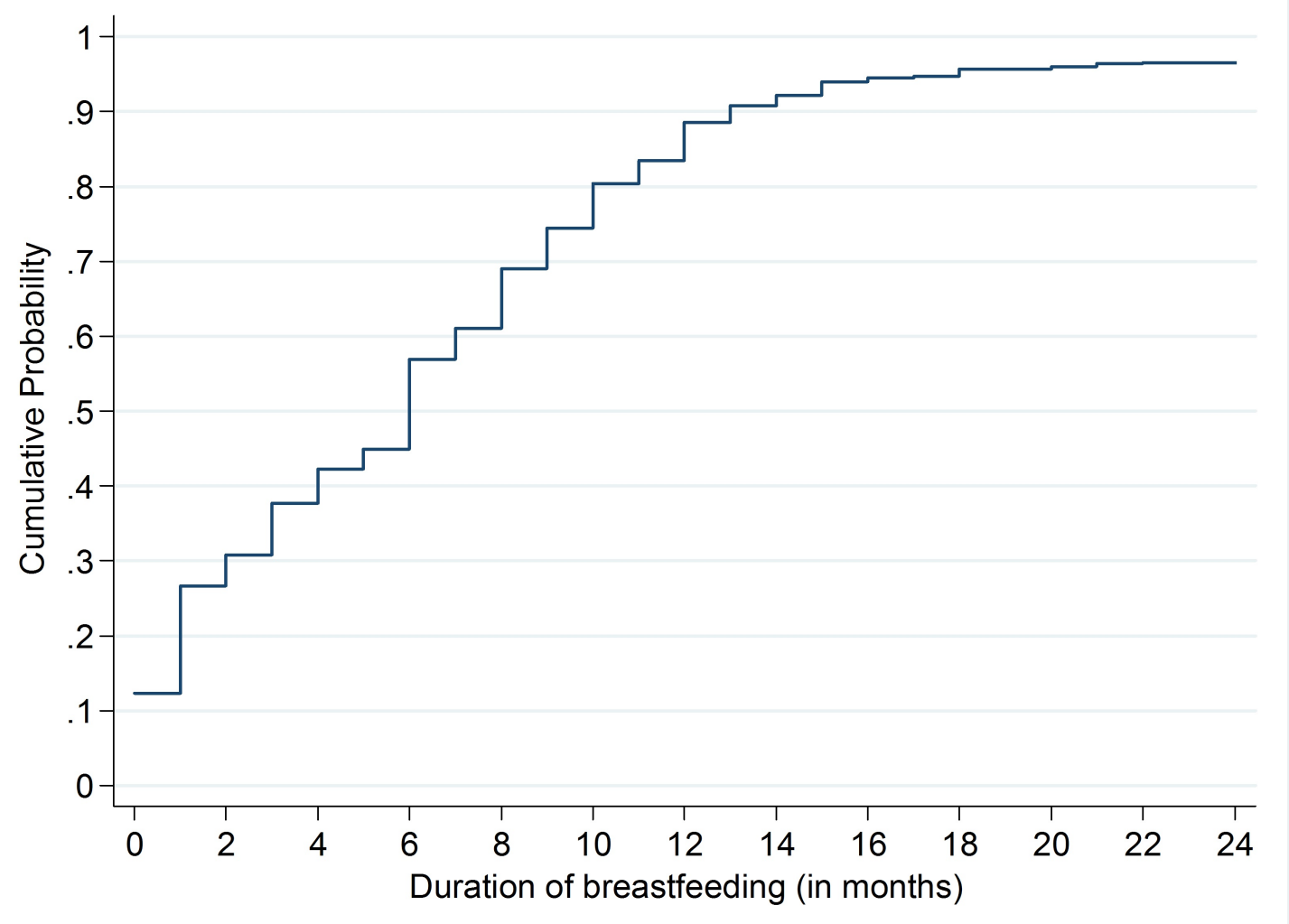

Figure A1: The distribution of breastfeeding durations in Germany for birth cohorts 2004-2007. Source: $\operatorname{SOEP}(2012) . N=552$. 

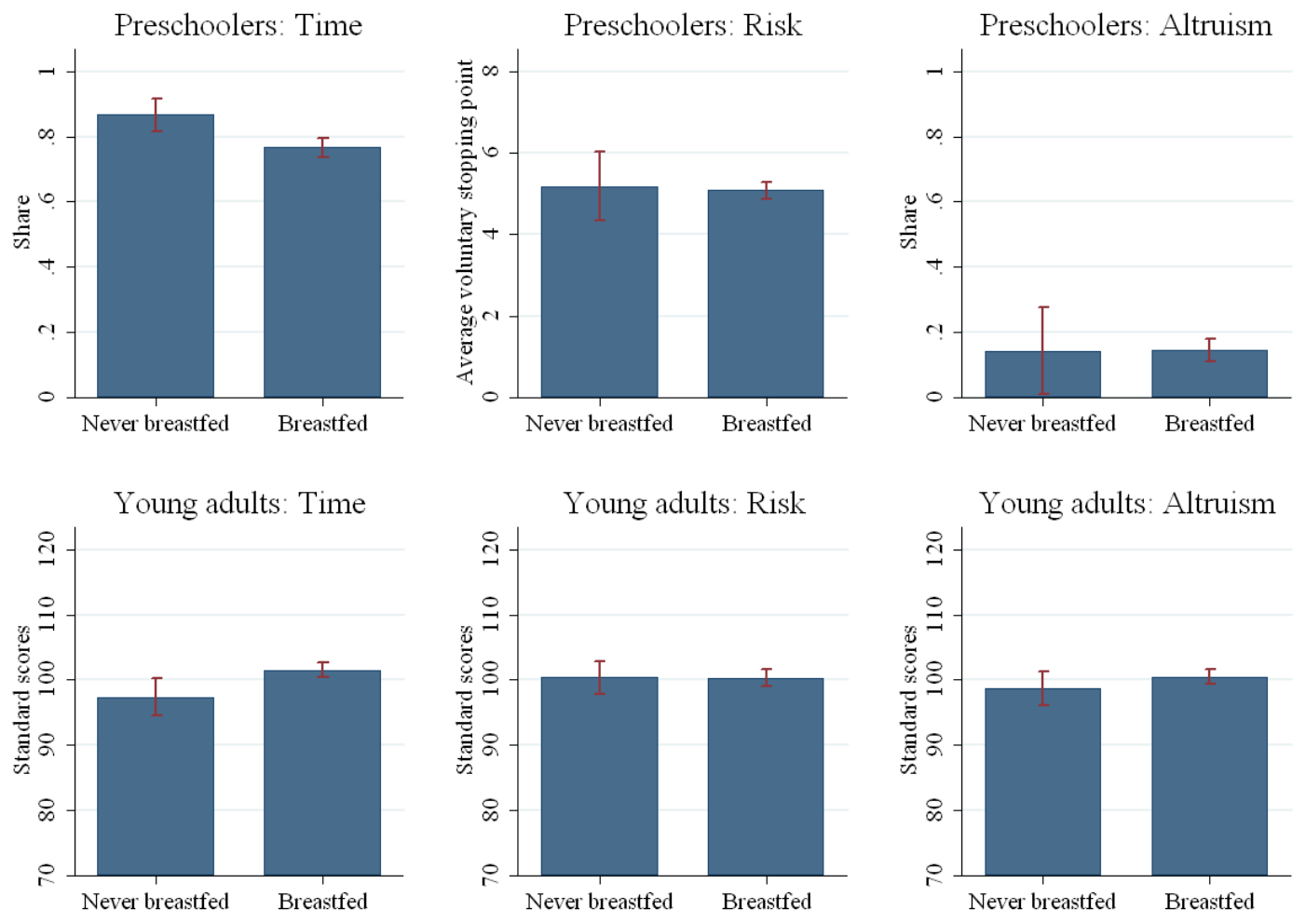

Figure A2: Comparison of preferences of breastfed and non-breastfed preschoolers and young adults. For young adults the $y$-axis indicates standardized scores (mean $=100$, standard deviation $=15$ ). Bars display the mean of the preference measure of the respective group. Error bars display standard errors of the means (SEM). None of the mean comparisons between breastfed and nonbreastfed individuals indicates a statistically significant difference at any conventional level (twosided $t$-test, numbers of observations between 110 and 267). To test the joint hypothesis of no difference in all six comparisons, we estimate the six regressions (preference on a dummy indicating breastfed or not) jointly in form of a generalized structural equation model (GSEM) and then use a $\chi^{2}$ test to test $\beta_{\text {dummy }}=0$ in all equations jointly: $\chi^{2}(6)=4.94, p=0.552, N=596$. 